\title{
Understanding of economic spillover mechanism by structural path analysis: a case study of interregional social accounting matrix focused on institutional sectors in Japan
}

\author{
Hidekazu Itoh $^{*}$
}

${ }^{*}$ Correspondence:

hito@kwansei.ac.jp

School of Business

Administration, Kwansei

Gakuin University,

Nishinomiya, Japan

\begin{abstract}
The aim of this research is to introduce a multiregional social accounting matrix (SAM) in Japan evaluating the regional and interregional spillover effects of economic impacts and to show the impact flows of economic linkages based on SAM. While research on national and regional SAM has become common, examples of interregional SAM are rare currently. This study points out that there is a substantial need to build a small regional and interregional SAM because of economic sensitivity. Our work evaluates the economic effects of national and regional government behavior, such as changes of the local tax system and decentralization of power, on the regional economy by structural path analysis. This research finds the differential impact flows of local government expenditures to regional incomes between a remote area and the rest of Japan (ROJ), or the leakages of remote area's money to ROJ via property income.
\end{abstract}

Keywords: Input-output table, Interregional social accounting matrix, Structural path analysis, Japan

JEL Classification: C67, E16, O53, R15

\section{Background}

Input-output (I-O) analysis (Miller and Blair 1985), developed by the Russian economist Wassily W. Leontief (1906-1999), is an effective tool to evaluate the mutual spatial effects of regional economies. I-O analysis is a systematic tool to analyze the relationship between industries through the production activities of each industry in a nation and region. To this day, the tool is used for empirical and advanced research. In Japan, the I-O table is compiled by prefectures, government-designated cities, and the national government, and an analysis based on the I-O table is used widely. Because the main purpose of $\mathrm{I}-\mathrm{O}$ analysis is to discuss the money flows or exchanges between only industries, this analysis does not consider all money flows, such as money exchanges with institutional sectors (household, company, and central and local governments) and fund flows with capital accounts (saving/investment). ${ }^{1}$

\footnotetext{
${ }^{1}$ See Itoh and Doi (2008) for the endogenizing consumption model in the I-O analysis.
}

(C) 2016 The Author(s). This article is distributed under the terms of the Creative Commons Attribution 4.0 International License (http://creativecommons.org/licenses/by/4.0/), which permits unrestricted use, distribution, and reproduction in any medium, provided you give appropriate credit to the original author(s) and the source, provide a link to the Creative Commons license, and indicate if changes were made. 
To meet this challenge, the social accounting matrix (SAM), developed by Sir J. Richard N. Stone (1913-1991), ${ }^{2}$ uses the I-O table as a basis to indicate all money exchanges at the same point in time and covers the activities of all economic agents: industry, capital, household, company, government, and the rest of the world (ROW). Therefore, the SAM at the level of a country or region shows the economic size and all money exchanges at each sector in that country or region.

The aim of this study is to introduce an analytical framework of interregional SAM (ISAM) focusing on institutional sectors based on data availability in Japan. In addition, the study aims to evaluate SAM multipliers and the regional and interregional spillover effects of economic impacts by using (spatial) structural path analysis (SPA), which is one tool of structural decomposition analyses (SDAs), for an ISAM constructed.

The following two points summarize the contribution of this study. First, the construction of ISAM focuses on detailed institutional sectors. ISAM constructed in early research (Itoh 2008b) essentially has four main categories as institutional sectors: household, company, local government, and saving/investment. Moreover, the ISAM proposed in this study has much more detailed categories, especially for companies and governments. For example, by applying this ISAM for empirical analysis, we can analyze the interdependent relationships between social security funds, taxes, and subsidies in local and central governments. In addition, because the ISAM constructed in the early research is based on the lists of more detailed income/expenditure following the system of national accounts (SNA) in Japan, balanced adjustments of the data gaps of sectors on ISAM are quite easy. The second contribution is that this empirical study applies SPA for ISAM in the flow analysis of spillover effects for regional incomes. This study undertakes a comparative analysis of regional economic spillover mechanisms for household incomes in regions based on the ISAM database with Hokkaido prefecture and the rest of Japan (ROJ).

The remainder of this paper is organized as follows: Section 2 explains the purpose and orientation of this research. Section 3 shows the frameworks of intraregional and interregional SAMs and proposes an ISAM with detailed institutional sectors by introducing the data possibilities of SNA in Japan. Moreover, this section provides an ISAM with two regions, focusing on Hokkaido prefecture. Next, Sect. 4 explains the method of spatial SPA, discusses the detailed regional and interregional economic spillover effects, and analyzes the results of the numerical example of the Hokkaido ISAM. Lastly, Sect. 5 concludes the research and gives direction for further research.

\section{Research motivation}

SAM is a comprehensive, disaggregated, consistent, and complete data system that captures the interdependent relationships within a social economic system for a single country or region. The sectoral classifications in most research using SAM are very rough because of data limitations. For example, a typical SAM has only household, company, and government as institutional sectors. However, detailed classification would be needed for analysis on issues that involve decentralization of power, like taxes, subsidies, and social security funds.

\footnotetext{
${ }^{2}$ See Stone and Croft-Murray (1959) for early research by Stone on SAM.
} 
In this research, we propose to construct an ISAM with detailed institutional sectors-including local governments, or local agencies of central government, prefectures, municipalities, and social security funds-in each region. Moreover, we evaluate the regional economic spillover effects for household income and discuss the differences of economic spillover mechanisms by applying spatial SPA for an ISAM constructed. This study presents an analytical framework of ISAM with detailed classification for Japan.

\subsection{Research purpose}

At the project level, like public investment and economic policy, specific sectoral costs are changed. Thus, the traditional partial equilibrium model, for example cost-benefit analysis (CBA), which is applied for policy evaluation, has some implications for the financial evaluation and economic efficiency of the relevant sectors. However, these methods cannot provide policy evaluation for the important structural changes to various other sectors; the methods can evaluate only the relevant sectors and cannot evaluate the interdependent relationships between production and consumption, prices of intermediate and final goods and services, and the money flows of income/expenditure at sectors. Therefore, computable general equilibrium (CGE) $)^{3}$ models based on the SAM database are applied as a useful tool for the evaluation of all sectors in the regional economy for economic policy, like regulation and interposition, relaxation of regulations, liberalization of trade, labor market, public finance, banking, transportation, and environment. Over the past few decades, CGE models have been adapted in many research fields other than economics, such as civil engineering, and research outcome has accumulated. ${ }^{4}$

Moreover, interregional models are needed for the analysis to consider time-space factors, like trade and transportation, because of the limitations with the model analysis using SAM and CGE for a single country or region. That is, although the demand for goods and services is primary demand, in general, transportation demand is derivative demand. For example, the new regulation for $\mathrm{CO}_{2}$ emission will affect shippers' modal choice from truck transport to freight rail and domestic sea transports in order to reduce greenhouse gas emissions and shippers' relocations of production and distribution facilities to reduce total logistics costs. Therefore, the networks of freight movements change their supply chain drastically according to transport infrastructure investment, transport efficiencies' improvements and $\mathrm{CO}_{2}$ emissions reduction too.

The purpose of this research is to introduce an analytical framework of ISAM and to undertake numerical analysis based on the ISAM database for discussing interregional economic spillover mechanisms. This study confirms the importance and challenges of ISAM construction. The analysis based on the SAM database can deal with income transfers in detail by considering not only the money flows between industries but also the money flows between institutional sectors (household, company, and government) and production

\footnotetext{
${ }^{3}$ SAM is a very useful analytical tool. However, similar to I-O analysis, SAM assumes that the prices of goods and production factors, production technology (input coefficients), and the allocation of production factors are stable. Thus, SAM analyzes only the regional economic spillover effects by an increase in final demand under a constant (stable) production structure in the short term.

4 See Donaghy (2009) for a recent survey of CGE models and Doi (2006) for recent empirical analyses using CGE models.
} 
factors (capital and labor). However, most of the early research using SAMs, including CGE models, is for a single country and region because of the limitations for data collection and the difficulty of analytical tools' application. This research discusses an evaluation method for regional economic policy, whose importance is increasing for the progress of decentralization of central government to local governments, by providing the analytical frameworks of intraregional and interregional SAMs. Moreover, a (relatively small) regional economy is affected more than the national economy by price changes including transportation costs, the transfer of production factors, and interregional economic spillovers. Therefore, there is an increasing need for an analytical tool evaluating regional economic policy with consideration for various economic characteristics of regions. In this study, we introduce the analytical framework of ISAM for prefectures and government-designated cities as well as the method for constructing the SAM database based on Itoh (2008b). In addition, we discuss the analytical availability or the effectiveness of ISAM using SAM multiplier analysis and spatial SPA for the ISAM with two regions as a case study.

\subsection{Early research}

There is much early research for economy-wide model analysis (EMA), like SAM analysis and CGE models based on a SAM database, which analyzes the interdependent effects between industries and institutional sectors at a national level. However, although the need for intraregional and interregional models is quite high, the empirical research excluding theoretical analysis and numerical example is limited, except for a few foreign studies. For example, some articles discuss interregional SAM multiplier analysis; for Indonesia, Hidayat (1991a, b) and Hidayat and Damayanti (1992) construct interregional SAM for central and local regions (or two-region) and calculate the income re-distributional effects of fiscal decentralization. Moreover, Achjar et al. (2003) evaluate the interregional and intersectoral spillover effects by interregional block structure path analysis (IBSPA) proposed by Sonis et al. (1997) for Indonesia five-region interregional SAM (capital accounts and indirect tax; exogenous). Recently, Resosudarmo et al. (2009) discuss the regional difference in Indonesia and evaluate the impacts of decentralization of power for the detailed interregional SAM with five regions too. However, these articles do not discuss the economic spillover mechanism, or the impact flows between sectors, of linkage effects. For USA, Seung (2014) evaluates "leakage coefficients" proposed by Hughes and Holland (1994) discussing income leakage for two-regional SAM between Alaska and the rest of USA (saving/investment and central government; exogenous, and single local government). For Japan, but intraregional SAM, Kawakami (2006) evaluates "income redistributional effects" proposed by Roland-Holst and Sancho (1992) for regional SAM in Mie prefecture (central government; exogenous). In addition, for example, some researches (Miyagi 1998; Takeda and Ban 2008) apply Japanese ISAMs constructed for CGE analysis. However, because their main focus is CGE modeling, these articles do not provide detailed information sources for their ISAM database construction. Therefore, the discussion on data availability in Japan is one of this study's contributions.

In this empirical analysis, we apply (spatial) SPA, which is one tool of SDAs. SPA applied in this research is general method for discussing economic spillover effects. Although the need for empirical analysis in Japan is also high, the empirical research on prefectures and cities is limited (see Kawakami 2006), particularly for comparatively 
closed economic zones and isolated island regions, like Okinawa and Hokkaido prefectures. ${ }^{5}$ In addition, there is no any research discussing interregional linkage effects by Japanese ISAM and spatial SPA. The contribution of this research is to evaluate and discuss the spillover mechanism, or the intraregional and interregional impact flows to regional incomes at each region including the expenditure/receive of social security funds at regional levels, and direct/indirect taxes and property accounts at national level, by decomposing the behaviors of regional and central governments separately as endogenous sectors. For this empirical analysis, we apply the decomposing method of SAM multiplier(s) proposed by Defourny and Thorbecke (1984) for Japanese ISAM. In addition, the impact flows of SAM multiplier effects to regional income are depicted by spatial SPA focused on not only size of SAM multipliers but also the paths of them.

On the other hand, SNA, or national economic accounting, is used for making a national-level SAM in Japan. Similarly, regional (or prefectural) economic accounting is used for making regional and interregional SAMs. However, the data from this economic accounting are not sufficient for constructing a detailed regional and interregional SAMs database. Therefore, there is limited empirical research on detailed regional and interregional SAMs. In this research, we explain the data availability of regional economic accounting in Japan and propose an empirical framework of ISAM that records the detailed institutional sectors of household, company, and local and central governments.

\section{Construction of ISAM and empirical analysis in Japan}

In this section, first, we explain the general SAM structure for a single country or region. Then, we extend the normal intraregional SAM to interregional SAM and discuss the characteristics and analytical possibilities of ISAM. The ISAM proposed in this research is constructed using an Isard-type I-O table. The Isard-type I-O table, that is, the interregional I-O table with non-competitive domestic imports, considers intermediate goods from other regions and foreign countries as different goods to the relevant sector on the (own) region. Second, this section introduces the structure of the interregional I-O table and the characteristics of available regional economic accounting, or regional SNA, in Japan as the main statistics for the construction of ISAM. Finally, this section proposes a framework of ISAM in Japan considering data availability and produces an ISAM with two regions, Hokkaido and ROJ, based on the year 2000, which is discussed in the next section as a case study. The original interregional I-O table for ISAM is based on year 1995, which has 9 regions and 46 industrial sectors. The input coefficients of ISAM are updated by the RAS method (Bacharach 1970; Lynch 1986) to year 2000. The case study has aggregated 10 industrial sectors for SAM multiplier and spatial SPA calculation. We introduce the framework of ISAM constructed in Itoh (2008b) on this section and leave the data elicitation for ISAM database on the early research.

\subsection{Structure of SAM}

\subsubsection{Intraregional SAM}

SAM provides rich information on not only the economic situation of each sector but also the comprehensive (or global) economic circulation between sectors. The matrix is

${ }^{5}$ For example, Doi et al. (2006) constructed a CGE model for Hokkaido prefecture. 
constructed by economic sectors, like production activities, value added (or production factors), and institutional sectors as the rows and columns of the matrix, following three rules (Pyatt and Thorbecke 1976):

(A) A row and a column with the same number (of matrix) are the same economic sector.

(B) The sum of a row and a column with the same number is the same.

(C) Expenditure of a sector is in the column and income of a sector is in the row, and the values of them are reported at their intersection.

SAM simultaneously provides the information on not only sectoral balance of payments but also sectoral income/expenditure on transactions. Therefore, SAM clarifies actual economic circulation, including the distribution structure of value added, by constructing SAM with the above-mentioned three conditions. Moreover, because the production activities of SAM are the same as the structure of the I-O table, SAM clarifies not only the entire economic circulation but also the detailed structure of production activities by incorporating the I-O table's ratio(s) or the structure of supply and demand by goods and services for each sector (or industry). The SAM with detailed economic circulation provides the relationship between supply and demand of goods and services and keeps the principle of equivalent of three aspects.

Figure 1 shows the structure of simplified intraregional SAM, including the ROW for a single county or region. The crosswise (row) direction is income and the lengthwise (column) direction is expenditure. Here, we show the economic spillover mechanisms (by arrows) from the demand increase in exports by the "ROW" in Fig. 1. "Industry" creates value added by producing goods or services for the export demand. The purchase of goods and services for production and consumption from the "ROW" is treated as imports, without distinguishing between intermediate goods and final goods. Some of the value added of "Capital" is redistributed to households of "Institute" as income for the labor of "Capital." Moreover, there is a transfer of money through taxes and subsidies within "Institute," and then, households of "Institute" consume goods and services from posttax income, and the production of "Industry" is reinduced by the consumption demand of households. The SAM analysis can provide the paths of the economic spillover mechanism. Here, because the shaded areas in Fig. 1 are considered in the analysis of the I-O table, such I-O analysis cannot discuss the impacts through income redistribution by institutes and industries via capitals (or labor).

\begin{tabular}{|l|c|c|c|c|}
\hline & Industry & Capital & Institute & ROW \\
\hline Industry & Production & & Consumption & Export \\
\hline Capital & VA & & & \\
\hline Institute & & Income & Transfer & \\
\hline ROW & Import & & & \\
\hline
\end{tabular}

Fig. 1 Structure of Intraregional SAM. Note ROW is "the rest of the world" and VA is "value added."This figure does not consider a "saving/investment" function as a subsidiary unit of the institutional sector for simplification. Therefore, this figure assumes that the sector, including households, must consume all disposable income in a year; in other words, there are no savings. Source Author's construction 


\subsubsection{Interregional SAM}

Here, we provide a possible framework of ISAM for a number of regions. This discussion supposes an ISAM in Japan, as we see later in this section, or thinking of an Isard-type (interregional) I-O table. Figure 2 presents the structure of interregional SAM simplified for two regions, including the ROW. As shown in Fig. 2, there are two differences between the models for a single region (Fig. 1) and two regions (Fig. 2). One difference is the interregional distribution of value added of industry, or the rewards of labor and the operational surpluses of capital. For example, the value added by production of "Industry" in Region 1 is distributed to Regions 1 and 2 based on the locations (or distribution) of suppliers of labor and capital for the production. The second difference is the treatment of exports and imports. Goods or services purchased from Region 2 by Region 1 as intermediate goods (or final consumption goods) are considered as inputs for the production (or imports for consumption). On the other hand, purchases of goods and services (intermediate goods and final goods) from the ROW are reported as just imports. As discussed before, one of the characteristics of interregional SAM is the detailed reports of money flows between industries and institutes via capitals in Regions 1 and 2. Similar to Fig. 1, Fig. 2 shows the economic spillover mechanisms (by arrows) for Region 1 of an export demand increase by the "ROW." Again, similar to Fig. 1, the shaded areas in Fig. 2 are considered only for the analysis of the interregional I-O table.

\subsection{Utilization data for interregional SAM construction}

This subsection explains the main data sources needed for constructing an intraregional and interregional SAM. We show: (1) the interregional I-O table providing the information about production technology (or input coefficients) of each industrial sector and (2) the regional economic accounting (or regional SNA) providing the information about income/expenditure of institutions, for example, household, company, and local and central governments.

\subsubsection{Interregional input-output table in Japan}

The interregional I-O table, which is the principal data for constructing ISAM for many regions at the same time, is constructed for interregional economic spillover analysis through interdependent interregional relationships. In Japan, the preparation

\begin{tabular}{|c|c|c|c|c|c|c|c|c|}
\hline & & \multicolumn{3}{|c|}{ Region 1} & \multicolumn{3}{|c|}{ Region 2} & \multirow{2}{*}{ ROW } \\
\hline & & Industry & Capital & Institute & Industry & Capital & Institute & \\
\hline \multirow{3}{*}{$\begin{array}{c}\text { Region } \\
1\end{array}$} & Industry & Production & & Consumption & Input & & Import & Export \\
\hline & Capital & $A$ & & 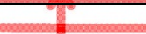 & $\mathrm{VA}$ & & & \\
\hline & Institute & L & Income & Transfer & & & & \\
\hline \multirow{3}{*}{$\begin{array}{c}\text { Region } \\
2\end{array}$} & Industry & Input & & Import & roduction & & Consumption & Export \\
\hline & Capital & VA & & & VA & & 8 & \\
\hline & Institute & & & & & Income & Transfer & \\
\hline \multicolumn{2}{|c|}{ ROW } & Import & & & Import & & & \\
\hline
\end{tabular}

Fig. 2 Structure of Interregional SAM. Notes ROW is "the rest of the world" and VA is "value added." As in Fig. 1, this figure does not consider a "saving/investment" function as a subsidiary unit of the institutional sector for simplification. Therefore, this figure assumes that the sector, including households, must consume all disposable income in a year; in other words, there are no savings. Source Author's construction 
of intraregional I-O tables is a joint project by the Ministry of Economy, Trade and Industry (METI), Cabinet Office, governments of Japan, Okinawa General Bureau, and Okinawa prefecture. The intraregional I-O tables, divided by nine Japanese regions, ${ }^{6}$ has been constructed at 5-year intervals after 1960. In addition, METI's research and statistics department have published the interregional I-O table connecting the above-mentioned intraregional I-O tables.

The intraregional I-O table shows the trade (money) flows of goods and services for a specific region within a certain period, similar to the I-O table for a single country or prefecture. The analysis based on the table is limited to show the trade flows in the relevant region. On the other hand, the interregional I-O table includes the economic activities of some regions on a single table and shows the trade flows of goods and services not only in the relevant region but also between regions. In particular, on the intraregional I-O table, the goods and services provided to other domestic regions from the relevant (own) region are accounted for as "exports," and the sum of exported goods and services is noted only on each sector. However, the goods and services produced in each sector of regions are accounted as the volume inputted (intermediate ones) or consumed (final ones) by each sector in regions on the interregional I-O table ${ }^{7}$; alternatively, the value of goods and services shows the quantity of non-competing goods and services inputted or consumed by industries of each region. Thus, the interregional I-O table enables us to discuss not only the industrial trade flow structures between sectors of regions but also some interregional spillover effects, which are never discussed on the intraregional I-O table and (general) I-O table for a single country or prefecture.

\subsubsection{National (or regional) economic accounting}

The SNA (or national economic accounting) is an international standard that systematically records both the flows of production, consumption, and investment, and the stocks of assets and debt for the national (or prefectural) economy.

For constructing the regional (or intraregional) SAM at the level of prefectures, the economic accounting at the level of prefecture (or regional SNA) is needed as the main statistics in addition to the regional I-O table of the relevant prefecture. Moreover, each dataset is required for the construction of intraregional SAM at the level of the municipality, which is lower than prefecture level. In addition to the regional I-O table, because regional economic accounting is published in all Japanese prefectures, the basic data source for constructing regional SAMs is available. In particular, we are able to use the following table that is included in prefectural economic accounting: "sectoral incomeexpenditure transactions of general governments (SIET) table." Here, the SIET table has rich information on income-expenditure transactions between four institutional sectors: (1) local agencies of central government, (2) prefectural governments, (3) municipal governments, and (4) social security funds, ${ }^{8}$ and is certainly needed to construct the detailed interregional SAM proposed in this study.

\footnotetext{
${ }^{6}$ Hokkaido, Tohoku, Kanto, Chubu, Kinki, Chugoku, Shikoku, Kyushu, and Okinawa (nine regions).

7 This interregional I-O table is known as the Isard-type I-O table. For detailed interregional I-O analysis, see Chapter 3 of Isard et al. (1998). In addition, the interregional I-O table is officially made up only in Japan; therefore, the discussion in this research provides useful information

${ }^{8}$ See Table 1 in Itoh (2008b) for an actual table (in Japanese) for Hokkaido prefecture.
} 
Table 1 Classification of accounts on ISAM. Source: Author's construction

(a) Endogenous sectors, each region (Hokkaido pref. and the rest of Japan (ROJ))

\begin{tabular}{|c|c|c|c|}
\hline & & Normal SAM & SAM proposed in this research \\
\hline Production activities & & $\begin{array}{l}\text { Industry } \\
\text { Goods and services }\end{array}$ & $\begin{array}{l}\text { Industry (see, subtable (d) in details) } \\
\text { Goods and services }\end{array}$ \\
\hline Production factors & & $\begin{array}{l}\text { Labor } \\
\text { Capital }\end{array}$ & $\begin{array}{l}\text { Labor } \\
\text { Capital }\end{array}$ \\
\hline \multirow[t]{4}{*}{ Institution sectors } & Current accounts & Household & Household (single category) \\
\hline & & Company & $\begin{array}{l}\text { Private NPO for household } \\
\text { Non-finance company } \\
\text { Finance company }\end{array}$ \\
\hline & & $\begin{array}{l}\text { Local Government } \\
\text { (Prefecture) }\end{array}$ & $\begin{array}{l}\text { Local agency of central Gov. } \\
\text { Prefecture } \\
\text { City, town and village } \\
\text { Social security funds }\end{array}$ \\
\hline & Capital accounts & Saving/investment & Saving/investment \\
\hline
\end{tabular}

(b) Endogenous sectors, "other part" (not included in above each region, subtable (a))

Direct tax

Indirect tax

Property income

Other sectors

Central Gov.

\section{(c) Exogenous sectors}

Export/import

(d) 10 Industrial sectors

\begin{tabular}{ll}
\hline Sector 1 & Agriculture, forestry and fisheries industry \\
Sector 2 & Mining \\
Sector 3 & Non-durable goods manufacturing \\
Sector 4 & Infrastructure equipment manufacturing \\
Sector 5 & Durable goods manufacturing \\
Sector 6 & Construction \\
Sector 7 & Electric, gas, heat and water supply, and waste \\
Sector 8 & Commerce \\
Sector 9 & Transportation \\
Sector 10 & Other services
\end{tabular}

In this empirical analysis, 10 industrial classifications are obtained by aggregating the publicly available interregional I-O table with 46 industrial sectors. One of the advantages of economy-wide model analysis (EMA) is its ability to evaluate the economic impacts on the regional economy by the differences between trade patterns and industries. For discussing the impacts on regional economies according to their differences of distribution systems, this SAM uses the commercial (commerce margin) and transportation (transport margin) sectors that are independent from other services. See Itoh (2008b) for details

The general rule for editing regional economic accounting at the level of prefectures is standardized by the Economic and Social Research Institute (ESRI) in Japan. However, there is no standardized rule for editing an SIET table. Therefore, only 13 of 47 prefectures in Japan ${ }^{9}$ publish this table on their regional economic accountings. In addition, for

\footnotetext{
${ }^{9}$ The 13 prefectures in Japan are Hokkaido, Aomori, Iwate, Akita, Miyagi, Ibaraki, Niigata, Nagano, Aichi, Hyogo, Okayama, Saga, and Okinawa.
} 
government-designated cities, whose level is lower than prefecture level, only Osaka city publishes a part of this kind of table. Some of government-designated cities make neither the SIET table nor their regional economic accounting per se, including the regional I-O table. If such a table is available, we can construct regional SAMs that indicate the money flows between central and regional governments or more detailed institutional sectors and evaluate the economic impacts by the transfers of tax revenue and subsidies from central to regional governments on the intraregional or interregional SAMs.

\subsubsection{Challenges for regional (interregional) SAM construction}

In general, this empirical study applies the ISAM shown conceptually in Fig. 2 by using the interregional $\mathrm{I}-\mathrm{O}$ table and regional and national economic accounting in Japan. Because the total income and expenditure of each sector must be the same under a characteristic of SAM conditions, as discussed in Sect. 3.1, the sums of each sectoral row and column in ISAM must also be the same. However, owing to the differences of data estimation methods in various statistics yearbooks of Japan, the total expenditure does not match the total income in some sectors. For example, although the I-O table is based on the calendar year, national economic accounting (or SNA) is based on the fiscal year in Japan. Therefore, there is a natural gap of a quarter of a year. In addition, the data estimation methods of indirect taxes differ from Japanese yearbooks. In this research, we apply the RAS method, which is a sequential matrix modification method, for adjusting these gaps of values at each sector on ISAM for empirical analysis.

In the end, the challenges in the application of economic accounting data for SAM construction are the gaps of data estimation methods for editing statistical yearbooks, and the differential items between data listings in national and regional statistical yearbooks.

\subsection{Analytical framework of ISAM construction and empirical analysis in Japan}

\subsubsection{Analytical framework of ISAM construction}

In this empirical analysis, we introduce a detailed analytical framework, or structure, of ISAM focusing on income/expenditure, or money flows, of institutional sectors in two regions and "other part" (endogenous), and the ROW (exogenous; see Table 1). The basic steps for the ISAM construction with more than two regions are the same as this one; however, the volumes of dataset required for them make it difficult to construct the ISAM.

Table 1 shows the framework of ISAM with two regions (Hokkaido and another region, or ROJ, in Japan), for the empirical analysis in Sect. 4. Each region has "production activities (industry, goods, and services)," "production factors (labor and capital)," and "institutional sectors (see below)." Moreover, this ISAM has "other part (endogenous sectors at the national level, see Table 1)," including direct and indirect taxes, property income, other sectors (other current transfers), and central government, which does not form at each region, and lastly, foreign accounts (exogenous sectors, export and import of goods and services). ${ }^{10}$

A rather important characteristic of ISAM proposed in this research is the creation of trade flows with institutional sectors in precise detail following the regional SNA in

${ }^{10}$ See Appendix 1 in Itoh (2008b) for the data elicitation of each cell in the ISAM database. 
Japan. The institutional sectors are divided into "current accounts (in general, household, company, and local government)" and "capital accounts (saving/investment)." Moreover, the current accounts are totally classified into eight sectors (see Table 1).

We can consider the detailed money flows of social costs and benefits by specifying four categories (see Table 1) of local government (prefectures and municipalities) based on an SIET table. In addition, we can discuss the redistribution of taxes in detail using indirect taxes (taxes for production and imported goods) and direct taxes (ordinary taxes for incomes and wealth) and the flows of monetary assets as independent accounts on "other part" (endogenous).

\subsubsection{Empirical analysis of Hokkaido ISAM}

For empirical analysis, we construct the ISAM database with two regions by using the interregional I-O table and national and prefectural economic accounting in Japan. In particular, the two regions on ISAM are Hokkaido prefecture and another region of 46 prefectures, or ROJ. Hokkaido is an independent region on the interregional I-O table in Japan, and the detailed SIET table at Hokkaido is publicly available. Therefore, Hokkaido would be a better region for construction of the ISAM proposed in this research. The ISAM for empirical analysis is based on the year 2000. Moreover, the case study of Hokkaido would be a very good example to understand the characteristics of ISAM framework because the distribution systems of transportation and commerce are very important in this isolated region. In addition, the Hokkaido economy suffers from a very difficult economic situation under the reduction in public works projects. Meanwhile, the official interregional I-O table for the year 2000 is not publicly available. ${ }^{11}$ Therefore, we apply technology coefficients between industries on regions (or input coefficients in the interregional I-O table) from the database in 1995, and other information from national and regional economic accountings in 2000. ${ }^{12}$

The difference between the proposed ISAM with two regions (Table 1) and actual Hokkaido ISAM database for this empirical analysis is the treatment of local government (prefectural level). Because the SIET table of Hokkaido is publicly available (see footnote 9), detailed information is available about the four sectors in local and central governments. However, the classified information for local government is not available for the other region(s), or the sum of 46 prefectures, because we have to apply essentially the information on SNA (or national economic accounting), which includes only the central government, regional government, and social security funds at national level, and this is a different classification to the prefectural information on regional economic accounting. Therefore, the Hokkaido ISAM for this empirical analysis has an aggregated "local government" of three sectors (local agency of central government, prefecture, and municipality) and "social security funds" for both regions in our comparative analysis of the economic spillover mechanism in Sect. 4.

\footnotetext{
11 The official interregional I-O table in 2000 is still unavailability because of institutional constraint, and the ISAM database for this empirical analysis is based on research outcome in Itoh (2008b). However, currently, the official interregional I-O table in 2005 is available publicly since March 2010. http://www.meti.go.jp/english/statistics/tyo/ tiikiio/index.html.

12 Because of space constraints, this paper omits an actual Hokkaido ISAM database: there are, in total, 45 rows and 45 columns, including export/import and the sums of rows and columns. Please contact Hidekazu ITOH at hito@kwansei. ac.jp to obtain the Japanese ISAM.
} 


\section{Analysis of economic spillover mechanism on Hokkaido ISAM}

In this section, we discuss the economic spillover mechanisms by applying SAM multiplier analysis for the Hokkaido ISAM developed in Sect. 3 as a case study. Next, we show the analytical challenges of SAM multipliers and introduce the spatial SPA, which is an advanced analytical tool for studying economic structures, or the impact flows of economic spillovers, on the ISAM. As a numerical example, this section discusses the differences of economic spillover mechanisms of Hokkaido and the other Japanese region by comparing in detail the flows of economic impacts on their household incomes.

\subsection{SAM multiplier analysis}

This subsection shows the possibility of ISAM analysis by undertaking empirical analysis of the economic interdependence of both regions for the Hokkaido ISAM constructed in this study. For the classification of industrial sectors presenting the input coefficients of the interregional I-O table, this research uses the 10 aggregated industrial sectors based on the 46 interregional I-O tables in Japan (see Table 1). In this empirical analysis, we apply the decomposition method for the degrees of interregional economic interdependence by Round (1985) and Pyatt and Round (1979). ${ }^{13}$

Here, $y$ is the column vector of total expenditure (=total income) of each sector, $x$ is the column vector of (total) exogenous sector(s), and $B$ is the component matrix of SAM, which is similar concept to the input coefficient matrix of the I-O table. In addition, to match the empirical analysis of this study, we decompose each vector, $y$ and $x$, and matrix $B$ into three parts with two regions (Hokkaido and ROJ) and "other part" (see Table 1). By solving Eq. (1) for $y$, we take Eq. (2). $M$ shows the interregional "Global Multiplier Effects (GMEs)," or SAM multipliers. That is, the components of this matrix $(M)$ indicate the income increase at each sector for a unit increase in exogenous demand (i.e., exports in this ISAM).

$$
\begin{aligned}
& y=B y+x \\
& y=(I-B)^{-1} x=M x
\end{aligned}
$$

Moreover, considering $B_{i i}$, which indicates a submatrix with expenditure from some sector of region $i$ to each sector of region $i$, and $\hat{b}_{i j}$, which indicates a submatrix with expenditure from some sector of region $i$ to each sector of region $j$, Eq. (1) is converted to Eq. (3)

$$
\left[\begin{array}{l}
y_{1} \\
y_{2} \\
y_{3}
\end{array}\right]=\left[\begin{array}{lll}
B_{11} & \hat{b}_{12} & \hat{b}_{13} \\
\hat{b}_{21} & B_{22} & \hat{b}_{23} \\
\hat{b}_{31} & \hat{b}_{32} & B_{33}
\end{array}\right]\left[\begin{array}{l}
y_{1} \\
y_{2} \\
y_{3}
\end{array}\right]+\left[\begin{array}{l}
x_{1} \\
x_{2} \\
x_{3}
\end{array}\right]
$$

Moreover, by zoning (a) the part of income/expenditure within the own region, (b) the part of income/expenditure with the other region, and (c) the part of income/expenditure with "other part (or taxes and money transfers of central governments in this

\footnotetext{
${ }^{13}$ See Roberts (1998) for a recent empirical analysis discussing the decomposition method for the degree of interregional economic interdependences. The case study of this paper is for the northeast region in Scotland.
} 
ISAM)," and solving Eq. (3) to $y$, we can obtain Eqs. (4) and (5). In this empirical analysis, subscript 1 is Hokkaido, 2 is another region, or ROJ, and 3 is "other part. ${ }^{14 \text { " }}$

$$
\left[\begin{array}{l}
y_{1} \\
y_{2} \\
y_{3}
\end{array}\right]=\left[\begin{array}{ccc}
I & -D_{12} & -D_{13} \\
-D_{21} & I & -D_{23} \\
-D_{31} & -D_{32} & I
\end{array}\right]^{-1}\left[\begin{array}{ccc}
\left(I-B_{11}\right)^{-1} & 0 & 0 \\
0 & \left(I-B_{22}\right)^{-1} & 0 \\
0 & 0 & \left(I-B_{33}\right)^{-1}
\end{array}\right]\left[\begin{array}{l}
x_{1} \\
x_{2} \\
x_{3}
\end{array}\right]
$$

Here, $D_{i j}=\left(I-B_{i i}\right)^{-1} \hat{b}_{i j}$. Or,

$$
y=M_{r 2} M_{r 1} x
$$

In Eq. (5), $M_{r 2}$ is constructed by "Interregional Multiplier Effects (IEMEs)" between Regions 1 and 2, and the multiplier (spillover) effects between each region (1 and 2) and "other part," and $M_{r 1}$ is constructed by "Intraregional Multiplier Effects (IAMEs)" within each region (1 and 2) and the multiplier (spillover) effects within "other part."

For example, although the "household $(\mathrm{H})$ " in Hokkaido has a 1.314 (income) increase $(M)$ by a unit (expenditure) increase by the "local government $(\mathrm{H})$ " in Hokkaido, the multiplier effects $\left(M_{r 1}\right)$ from Hokkaido (own region) within the 1.314 (income) increase are just 0.940 , based on the results of the matrix calculation for Hokkaido ISAM. ${ }^{15}$

Based on this calculation, we can understand the income expanding mechanism $\left(M_{r 2}\right)$ of households in Hokkaido through the economic linkages with ROJ and "other part" having taxes and subsidies (or the "household" row for Hokkaido in $M_{r 2}$ ) after the (income) increase in each sector (or the "local government" column for Hokkaido in $M_{r 1}$ ) by the unit (expenditure) increase in "local government $(\mathrm{H})$ " in Hokkaido. ${ }^{16}$ In particular, the income increase via "households $(\mathrm{H})$," furthermore "other services $(\mathrm{H})$," and "local government $(\mathrm{H})$," is comparatively large in Hokkaido because of a closed and isolated economy. Similarly, "household (R)" in ROJ has a 8.698 (income) increase by a unit (expenditure) increase by the "local government (R)" of ROJ. In this income increase (8.698), because the impact of economic linkages inside the (own) region is just 1.600, the interdependent impacts with Hokkaido and "other part" are bigger than the case in Hokkaido. ${ }^{17}$ In particular, the (income) increase via "household (R)," "non-finance company $(\mathrm{R})$," and "local government $(\mathrm{R})$ " is comparatively large in ROJ.

As previously discussed, the advantage of SAM analysis is that it can evaluate in detail the transfers of income distribution in institutional sectors, including households. Table 2 summarizes the sectoral economic impacts on the household income of Hokkaido $(\mathrm{H})$ and $\mathrm{ROJ}(\mathrm{R})$ based on the size of the SAM multipliers (or GMEs) in decreasing

\footnotetext{
${ }^{14}$ See Appendix 3 in Itoh (2008b) for a detailed mathematical explanation about the decomposition method for the degree of interregional interdependence.

15 Because of the huge matrix with 43 rows and 43 columns, this paper does not insert the table of matrix.

16 In particular, this is the sum of products of the row vector (1-by-43) of "household $(\mathrm{H})$ " in Hokkaido with the column vector (43-by-1) of "local government $(\mathrm{H})$ " in Hokkaido.

17 The SAM multipliers of ROJ are much bigger than those of Hokkaido because these multipliers depend on the ISAM structure (or relative economic size and endogenous sectors). For example, because the gross regional product of Hokkaido is just $3.9 \%$ of the national total (the I-O table in 2000), the difference in economic size of both regions produces the differences in the SAM multipliers. Moreover, by keeping taxes, property income, and central government, or "other part," as exogenous sectors, the income increase in each household in Hokkaido and ROJ is just 0.955 and 1.625, respectively. In particular, the income increase in Hokkaido is less than 1.0. If "other part" is treated as exogenous one, the unit (expenditure) increase in "local government $(\mathrm{H})$ " does not contribute for "household $(\mathrm{H})$ " in Hokkaido. Conversely, we can understand that the impact of their expenditure in Hokkaido goes to "household (R)" in ROJ via property incomes and taxes, if the "other part" is treated as endogenous one.
} 
Table 2 SAM multipliers focused on household (HH) incomes by Hokkaido ISAM. Source: Author's construction

\begin{tabular}{|c|c|c|c|c|}
\hline & \multicolumn{2}{|l|}{ Hokkaido (H) } & \multicolumn{2}{|l|}{ The rest of Japan (R) } \\
\hline & Sectors & SAM multiplier & Sectors & SAM multiplier \\
\hline 1 & Labor $(H)$ & 1.997 & Labor (O) & 9.561 \\
\hline 2 & Commerce $(H)$ & 1.502 & Social security funds $(\mathrm{O})$ & 9.134 \\
\hline 3 & Transportation $(\mathrm{H})$ & 1.434 & Commerce $(\mathrm{O})$ & 9.095 \\
\hline 4 & Other services $(H)$ & 1.374 & Property Income & 8.991 \\
\hline 5 & Capital (H) & 1.320 & Other sector & 8.989 \\
\hline 6 & Local government $(\mathrm{H})$ & 1.314 & Finance company (O) & 8.867 \\
\hline 7 & Construction $(\mathrm{H})$ & 1.267 & Capital $(\mathrm{O})$ & 8.858 \\
\hline 8 & Utilities $(\mathrm{H})$ & 1.261 & Central government & 8.790 \\
\hline 9 & Social security funds $(H)$ & 1.234 & Other services $(O)$ & 8.774 \\
\hline 10 & Agriculture, etc. $(\mathrm{H})$ & 1.128 & Direct tax & 8.758 \\
\hline 11 & Private NPO for $\mathrm{HH}(\mathrm{H})$ & 1.111 & Indirect tax & 8.733 \\
\hline 12 & Infrastructure Manu. (H) & 1.084 & Local government $(\mathrm{O})$ & 8.698 \\
\hline 13 & Saving/investment $(\mathrm{H})$ & 1.037 & Finance company $(\mathrm{H})$ & 8.665 \\
\hline 14 & Non-durable Manu. (H) & 0.925 & Construction $(\mathrm{O})$ & 8.658 \\
\hline 15 & Non-finance company $(\mathrm{H})$ & 0.899 & Private $\mathrm{NPO}$ for $\mathrm{HH}(\mathrm{O})$ & 8.499 \\
\hline
\end{tabular}

order. The economic impacts from service sectors, including "commerce $(\mathrm{H})$ " and "transportation $(\mathrm{H})$," for "household $(\mathrm{H})$ " are comparatively large in Hokkaido. In addition, the capital sectors ("labor $(\mathrm{H})$ " and "capital $(\mathrm{H})$ ") directly have economic impacts for "household (H)." On the other hand, the economic impacts on "household (R)" from "property income," "other sectors," and "central government," or from "other part," are large in ROJ. Moreover, "household (R)" in ROJ is economically affected by not only "finance company (R)" in ROJ but also "finance company (H)" in Hokkaido focusing on finance companies' impacts in "current accounts."

\subsection{Structural path analysis of ISAM}

\subsubsection{Tool of structural path analysis ${ }^{18}$}

We evaluated the economic spillover effects by SAM multipliers in Sect. 4.1. SAM multipliers indicate the (total) economic impacts through the direct and indirect spillover impacts on some economic agent (or household) by a unit (expenditure) increase on some sector. For example, an (income) increase in "household (H)" in Hokkaido is 1.314 for a unit (expenditure) increase in "local government $(\mathrm{H})$ " in Hokkaido. Similarly, an (income) increase in "household (R)" in ROJ is 8.698 for a unit (expenditure) increase in "local government (R)" in ROJ. Even though it would be possible to decompose the SAM multipliers into intraregional (IAME) and interregional (IEME) spillover effects separately, we cannot distinguish the paths (or flows) of these effects or it is "black box." If we can understand the paths of economic impacts, or spillover effects, we can discuss which

\footnotetext{
${ }^{18}$ See Defourny and Thorbecke (1984) for initial research about SPA. Moreover, see Sonis and Hewings (1998) for recent research discussing SPA for interregional I-O tables.
} 
economic policy is effective and identify the sectors that are bottlenecks for regional economic development.

SPA is the analytical tool for this challenge. It can decompose the SAM multipliers from some sector $i$ (origin) to some sector $j$ (destination) into each sectoral connections, or the paths of economic links. For example, we can know the path from the expenditure of the Hokkaido local government (origin) to the increasing household income (destination) in Hokkaido and which sector contributes to the income increase. In other words, SPA can clarify the "black box" in SAM multipliers, that is, the structure and behavioral mechanism of the economic effects (or, GMEs). SPA provides a detailed method of decomposing SAM multipliers and of identifying the whole network of paths whose influence is transmitted from one sector of origin to the sector of ultimate destination, thereby opening the "black box."

Here, this part explains the analytical tool of SPA by using the empirical results for Hokkaido ISAM. Once again, the economic impacts on "household (H)" in Hokkaido by a unit (expenditure) increase in "local government $(\mathrm{H})$ " in Hokkaido, or the SAM multiplier $(G M E)$, are 1.314. For example, we pick up the spillover effects, as an example, via "other services $(\mathrm{H})$ " and "labor $(\mathrm{H})$ " within this (total) multiplier and define the effects as "Direct Effects" (DEs). Figure 3 shows this structural relationship. $c$ is "Marginal Expenditure Propensity," which is a similar concept of input coefficients. In particular, $c_{x i}$, or the expenditure on "other services $(\mathrm{H})$ " within the unit expenditure of "local government $(\mathrm{H})$," is 0.526 , which is from the results of calculation on the Hokkaido ISAM. Similarly, $c_{y x}$, or the expenditure on "labor $(\mathrm{H})$ " within the unit expenditure of "other services $(\mathrm{H})$," is 0.342 , and $c_{j y}$, or the expenditure on "household $(\mathrm{H})$ " within the unit expenditure of "labor $(\mathrm{H})$," is 1.000. Finally, the spillover effect on "household $(\mathrm{H})$ " from a unit expenditure increase in "local government $(\mathrm{H})$ " via "other services $(\mathrm{H})$ " and "labor $(\mathrm{H})$ " is $c_{x i} \times c_{y}$ ${ }_{x} \times c_{j y}=0.526 \times 0.342 \times 1.000=0.179$; this is equal to $D E$ (see Table 3$)$.

However, the effects on "household $(\mathrm{H})$ " from "other services $(\mathrm{H})$ " and "labor $(\mathrm{H})$ " are not only this $D E$ but also the other paths. For example, it is possible that some effects are brought indirectly to "household $(\mathrm{H})$ " via other sectors during the path from "other services $(\mathrm{H})$ " to "labor $(\mathrm{H})$." Therefore, we define this effect as "Path Effects" (PEs). In Fig. 3, these PEs are $c_{x y}$ and $c_{z y} \cdot c_{x z}$. The aggregated path effects with all direct and indirect

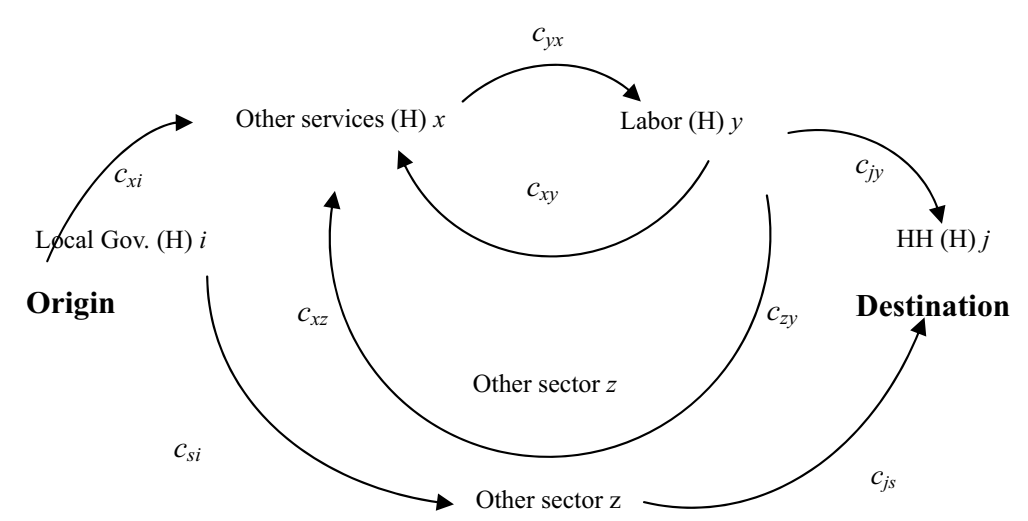

Fig. 3 Direct effect, path effect, and total effect. Note $C$ is the marginal expenditure propensity of each sector Source Author's construction, using Defourny and Thorbecke (1984, p. 121, Figure 3 ) as a reference 
Table 3 Economic spillover. Source: Author's construction

\begin{tabular}{lllll}
\hline Local Gov. $(\mathbf{H}) \boldsymbol{i} \rightarrow \mathbf{H H}(\mathbf{H}) \boldsymbol{j}$ via sectors & Direct effects & Path effects & Total effects & \% (Accu. \%) \\
\hline Other services $(H) \rightarrow$ Labor $(H)$ & 0.179 & 2.591 & 0.465 & $35.4(35.4)$ \\
(none) & 0.159 & 2.162 & 0.344 & $26.1(61.5)$ \\
Other services $(H) \rightarrow$ Capital $(H)$ & 0.054 & 2.714 & 0.146 & $11.1(72.6)$ \\
S/I $(H) \rightarrow$ Construction $(H) \rightarrow$ Labor $(H)$ & 0.020 & 2.316 & 0.045 & $3.5(76.1)$ \\
Social security funds $(H)$ & 0.012 & 2.260 & 0.027 & $2.1(78.2)$ \\
Other services $(H) \rightarrow$ Capital $(H) \rightarrow$ Non-finance & 0.005 & 2.725 & 0.013 & $1.0(79.2)$ \\
$\quad$ company $(H)$ & & & & $\ldots$ \\
$\ldots$ & $\ldots$ & $\ldots$ & 1.314 & $-(100.0)$ \\
\hline Sum (global multiplier effects $=$ SAM multiplier) & - & - & &
\end{tabular}

effects are defined as "Total Effects" (TEs). In this empirical analysis, the TE from "local government $(\mathrm{H})$ " to "household $(\mathrm{H})$ " is 0.465 ; then, the $P E$ is 2.591 , which is 0.465 divided by $0.179 .{ }^{19}$ In general, the $P E$ is proportionate to the number of sectors going through origin $i$ to destination $j$. This is understood economically as the duration time of economic impacts.

Moreover, the economic impacts (or spillover effects) from "local government $(\mathrm{H})$ " to "household $(\mathrm{H})$ " are not only via "other services $(\mathrm{H})$ " and "labor $(\mathrm{H})$ " but also other sectors. For example, the spillover effects on "household $(\mathrm{H})$ " via "social security funds $(\mathrm{H})$ " from "local government $(\mathrm{H})$ " has a TE of 0.027 (see Table 3). In this way, there are various paths for economic effects from "local government $(\mathrm{H})$ " as the origin $i$ to "household $(\mathrm{H})$ " as the destination $j$. The sum of all TE(s) is GME, which is the same for the SAM multiplier discussed in Sect. 4.1.

Table 3 shows the spillover effects from "local government $(\mathrm{H})$ " to "household $(\mathrm{H})$ " in decreasing order of $T E(\mathrm{~s})$. The $T E$ via only "other services $(\mathrm{H})$ " and "labor $(\mathrm{H})$ " is 0.465 , which is $35.4 \%$ for the SAM multiplier. In addition, the TE from "local government" directly (or no other connection with this sector) to "household $(\mathrm{H})$ " is just 0.344 , which is $26.1 \%$ for the SAM multiplier. The sum of the top six paths occupies about $80 \%$ of the SAM multiplier. We can observe and understand the differences of the economic spillover mechanisms on two regions by applying spatial SPA in detail.

\subsubsection{Results of empirical analysis}

This subsection compares and discusses the differences of the economic spillover mechanisms on Hokkaido $(\mathrm{H})$ and ROJ $(\mathrm{R})$ based on the spatial SPA results. We decompose the SAM multipliers for "household(s)" of Hokkaido (H) and ROJ (R) as the final destination. Figure 4 summarizes the economic spillover mechanisms, or structural paths, for household $(\mathrm{HH})$ in each region in decreasing order of $T E(\mathrm{~s})$ until the top 30 paths. To understand them easily, Fig. 4 is simplified by grouping some sectors with similar paths. Moreover, the <number $>$ with a sector in the figure shows the order of $T E(\mathrm{~s})$ of the sector as the origin for "household $(\mathrm{H})$ " in Hokkaido. Similarly, the [number] with a sector in the figure shows the order of $T E(\mathrm{~s})$ of the sector as the origin for "household (R)" in

\footnotetext{
19 The "Total Effect" $(T E)$ is defined as $c_{x i} c_{y x} c_{j y}\left[1-c_{y x}\left(c_{x y}+c_{z y} c_{x z}\right)\right]^{-1}$ in Fig. 3, and $[*]^{-1}$ is the "Path Effect" (PE). See Defourny and Thorbecke (1984) for details.
} 


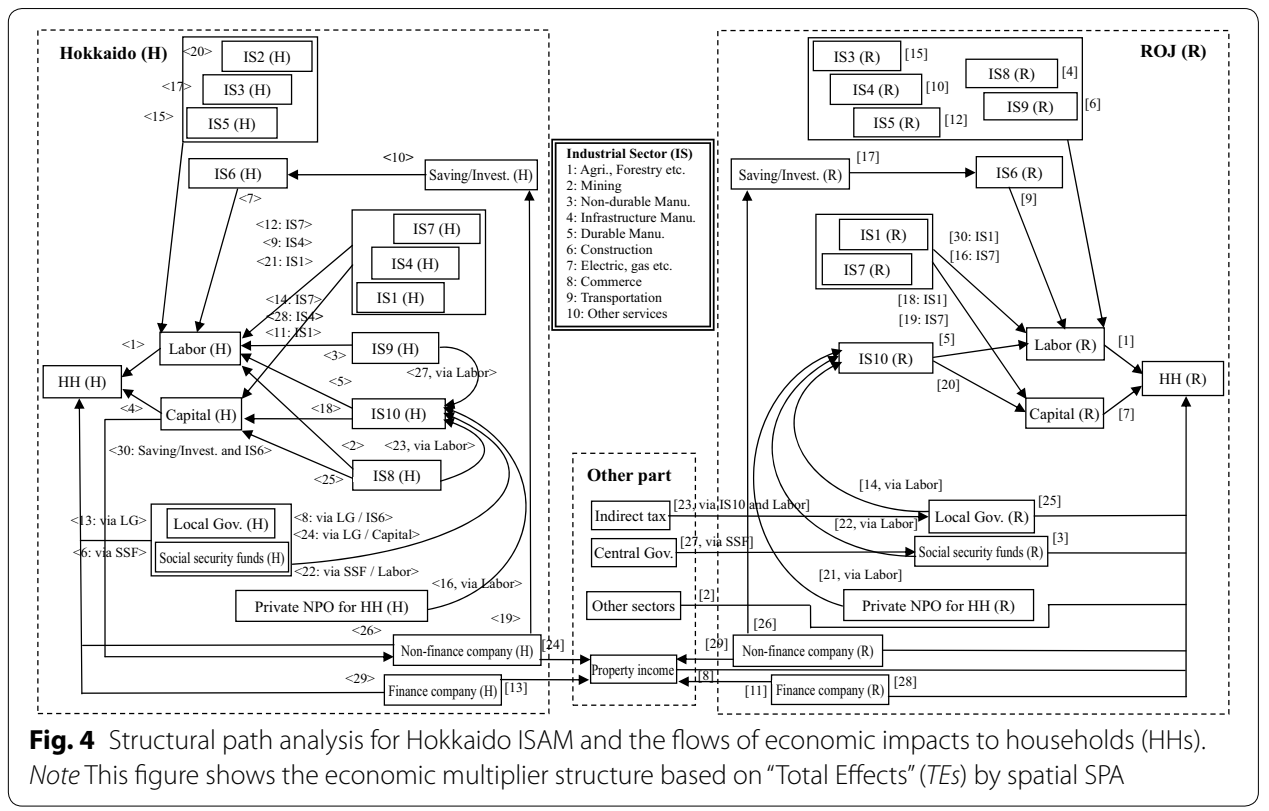

ROJ. For example, we can find a spillover path (the order of $T E$ is 19th) to "household $(\mathrm{H})$ " via "saving/investment $(\mathrm{H})$ " and "construction $(\mathrm{H})$ " from "non-finance company $(\mathrm{H})$ " as the origin. On the other hand, we can find a direct path (the order of $T E$ is 26th) to "household (H)" from "non-finance company $(\mathrm{H})$." Moreover, "non-finance company $(\mathrm{H})$ " affects not only "household $(\mathrm{H})$ " in Hokkaido but also "household $(\mathrm{R})$ " in ROJ via "property income" (the order of $T E$ is 24th) of "other part."

In this result, the comparison of the economic spillover mechanisms for household incomes between Hokkaido and ROJ shows some similar paths. Distinctively, there are significant spillover effects via "other services $(\mathrm{H})$ and $(\mathrm{R})$ " from "local government $(\mathrm{H})$ and (R)," "social security funds (H) and (R)," and "private non-profit organization (NPO)" for "household $(\mathrm{H})$ and $(\mathrm{R})$ " as the origins. ${ }^{20}$ Because "other services" include other public services and medical, healthcare, and social security services in the detailed 46 industrial sectors of the original interregional $\mathrm{I}-\mathrm{O}$ table, these paths are quite reasonable. Moreover, there is a significant path via "saving/investment $(H)$ and $(R)$ " and "construction $(\mathrm{H})$ and $(\mathrm{R})$ " from "non-finance company $(\mathrm{H})$ and $(\mathrm{R})$ " as the origins to household income. This result shows that much of company savings flows to construction investments in both regions.

However, for the different spillover mechanisms, the economic impacts via industrial sectors on Hokkaido are relatively higher than those in ROJ. For example, service industries, like "commerce $(\mathrm{H})$ " and "transportation $(\mathrm{H})$," affect household income not only directly via "labor $(\mathrm{H})$ " and "capital $(\mathrm{H})$ " but also via "other services $(\mathrm{H})$." However, although "commerce $(\mathrm{H})$ " has higher $T E(\mathrm{~s})$ via both "labor $(\mathrm{H})$ " and "capital $(\mathrm{H})$," "transport $(\mathrm{H})$ " has higher $T E$ only via "labor $(\mathrm{H})$." The order of the $T E$ via "capital $(\mathrm{H})$ " from "transport $(\mathrm{H})$ " is lower than 30th because the transportation industry is mainly

20 The spillover paths via industrial sectors go through production factors (capital and labor) just after the industry because of the structure of ISAM. 
consisted of labor-intensive truck carriers. In addition, although the economic impact is not so high (30th), the spillover effect from "capital $(\mathrm{H})$ " as the origin going though "non-finance company $(\mathrm{H})$," "saving/investment $(\mathrm{H})$," "construction $(\mathrm{H})$," and "labor $(\mathrm{H})$ " to household income in Hokkaido is distinguishable and different from the case in ROJ. Hokkaido's regional economic structure, or the economic spillover mechanism in Hokkaido, depends much more on construction investments.

On the other hand, the economic impacts from "other part" as the origin to household income in ROJ are higher than those in Hokkaido. For example, the "indirect tax" and "central government" as the origins affect household income via "local government (R)" and "social security funds (R)," respectively. Moreover, the function of "property income" for the economy in ROJ differs from the case of Hokkaido. Although this sector directly affects "household (R)" (the order of TE is 8th), the sector has been a hub of the economic impacts not only from "non-finance company (R)" (29th) and "finance company (R)" (11th) in ROJ but also from "non-finance company $(\mathrm{H})$ " (24th) and "finance company $(\mathrm{H})$ " (13th), which indirectly affect only household income in ROJ to some extent, in Hokkaido as the origins. That is, the money of Hokkaido's companies flows out of the intraregional economy in Hokkaido to the external economy, or to ROJ. Therefore, the size of income transfers (or subsidies) to Hokkaido's households from not only central government and industrial sectors in ROJ but also industrial sectors in Hokkaido is relatively small compared to the case in ROJ. Conversely, the size of economic impacts via service sectors, including commerce, transportation, and construction, on households in Hokkaido is relatively larger than the case in ROJ because of the update on logistics infrastructure and the introduction of modern distribution systems, which have more potent multiplier effects for the isolated Hokkaido's economy.

\section{Conclusion}

This study proposed an ISAM framework with detailed institutional sectors by considering the characteristics and availability of data in Japan. In particular, this study applied an ISAM with Hokkaido and ROJ based on the interregional I-O table for the year 2000 and national and prefectural economic accounting. This ISAM was built based on an Isard-type I-O table and considered in detail monetary exchanges of institutional sectors, especially local and central governments, social security funds, and some taxes and subsidies. Moreover, this study conducted a comparative analysis of the economic spillover mechanisms for household income of each region by applying an analytical tool of spatial SPA for the ISAM database as a case study, which enabled a discussion on the differences of the economic multiplier mechanisms in both regions.

For further research, we propose the following two directions. The first direction is a construction of multiregional SAM based on the analytical framework of this research. Because the original interregional $\mathrm{I}-\mathrm{O}$ table in Japan is for nine regions (two regions in the database for this study), the construction of multiregional SAM with regional characteristics of each region is needed. The second direction is a construction of multiregional (or spatial) CGE model by applying the database of this ISAM. An EMA that endogenizes price (or cost) mechanisms is available by incorporating the functions of income transfers between institutional sectors, especially central and regional governments, and the decision making of shippers and transport companies who use 
transportation and commercial services in SCGE. For example, the result of a modal shift analysis (see Itoh 2008a, for Japanese shippers), or the elasticity of transport modes by discrete choice analysis, would be incorporated in the functions of shippers (or manufacturers, wholesalers, and retailers) in the SCGE model. Because the regional economy has quite different and diverse characteristics compared with the national economy, the differences of transportation and distribution systems on each region would affect much more than at the national economy. However, because of data limitations, most of ISAM analyses, including SCGE analyses, are still for international and national levels.

\begin{abstract}
Acknowledgements
The idea for this research is based on a discussion during my sabbatical leave in 2006-2008 at the Regional Science Group, the Department of City and Regional Planning, Cornell University, with Prof. Iwan J. Azis, Prof. Kieran P. Donaghy, Emeritus Prof. Sidney Saltzman, and Emeritus Prof. Walter Isard, a founder of regional science who passed away on November 6, 2010. Moreover, I am extremely grateful for support with the numerical analysis of SPA by Prof. Azis, who is currently adjunct professor, Charles H. Dyson School of Applied Economics and Management at Cornell and professor of economics at the Faculty of Economics and Business, University of Indonesia since 2015, and the former head of regional economic integration at the Asian Development Bank between 2010 and 2014. I am responsible for any remaining
\end{abstract} errors.

This paper was presented at the conference of Korean Association of Economic Systems Research (KESRA), Seoul, South Korea, February 25, 2015

Received: 25 July 2015 Accepted: 16 July 2016

Published online: 03 August 2016

\title{
References
}

Achjar N, Hewings GJD, Sonis M (2003) Two-layer feedback loop structure of the regional economies of Indonesia: an interregional block structural path analysis. The Regional Economics Applications Laboratory (REAL), Discussion Paper, REAL 03-T-17, 1-28

Bacharach M (1970) Biproportional matrices and input-output change. Cambridge University Press, Cambridge

Defourny J, Thorbecke E (1984) Structural path analysis and multiplier decomposition within a social accounting matrix framework. Econ J 94(373):111-136

Doi M (ed) (2006) Computable general equilibrium approaches in urban and regional policy studies. World Scientific, Singapore

Doi M, Kimura K, Itoh H (2006) An analysis of economic impacts of transportation improvement for the remote Hokkaido Region. The Japan Research Center for Transport Policy, Nikkoken Series A-417, pp 1-17 (in Japanese)

Donaghy KP (2009) CGE modeling in space, a survey. In: Capello R, Nijkamp P (eds) Handbook of regional growth and development theories. Edward Elgar Publishing, Cheltenham, pp 66-85

Hidayat T (1991a) The construction of two-region social accounting matrix for Indonesia and its application to some equities issues. Unpublished Ph.D. Dissertation, Cornell University

Hidayat T (1991b) An interregional social accounting matrix for Indonesia: theoretical background and construction. Ekonomi dan keuangan Indonesia (EKI) 39(4):335-350

Hidayat T, Damayanti D (1992) Distributional effect of fiscal decentralization in Indonesia: an application of a linked econometric-IRSAM model. Ekonomi dan keuangan Indonesia (EKI) 40(3):247-277

Hughes D, Holland D (1994) Core-periphery economic linkage: a measure of spread and possible backwash effects for the Washington economy. Land Econ 70:364-377

Isard W, Azis IJ, Drennan MP, Miller RE, Saltzman S, Thorbecke E (1998) Methods of interregional and regional analysis. Ashgate Publishing Company, Vermont

Itoh H (2008a) An analysis of route choice model on cargo transport for modal shift policy: an application of random parameter logit model. J Jpn Logist Soc 16:201-208 (in Japanese)

Itoh H (2008b) An interregional SAM building focused on institutional sectors and structure path analysis. J Bus Adm 56(1):33-70 (in Japanese)

Itoh H, Doi M (2008) Endogenizing consumption in the input-output model: theory and application. Rev Urban Reg Dev Stud 20(2):151-166

Kawakami T (2006) Construction of regional social accounting matrices and a multiplier analysis of production/distribution structures. Input-Output Anal Innov I-O Tech 14(3):3-19 (in Japanese)

Lynch RG (1986) An assessment of the RAS method for updating input-output tables. In: Sohn I (ed) Readings in inputoutput analysis. Oxford University Press, New York, pp 271-284

Miller RE, Blair PD (1985) Input-output analysis: foundations and extensions. Prentice-Hall, New Jersey

Miyagi T (1998) A spatial computable general equilibrium approach for measuring multiregional impacts of large scale transportation projects. In: Lundqvist L, Mattsson LG, Kim TJ (eds) Network infrastructure and the urban environment. Springer, Berlin, pp 224-241

Pyatt G, Round JI (1979) Accounting and fixed price multipliers in a social accounting framework. Econ J 89:850-873 
Pyatt G, Thorbecke E (1976) Planning techniques for a better future. International Labour Organization (ILO), Geneva Resosudarmo BP, Nurdianto DA, Hartono D (2009) The Indonesian inter-regional social accounting matrix for fiscal decentralization analysis. J Indones Econ Bus 24(2):145-162

Roberts D (1998) Rural-urban interdependencies: analysis using an inter-regional SAM model. Eur Rev Agric Econ 25:506-527

Roland-Holst DW, Sancho F (1992) Relative income determination in the United States: a social accounting perspective. Rev Income Wealth 38(3):311-327

Round JI (1985) Decomposing multipliers for economic systems involving regional and world trade. Econ J 95:383-399 Seung CK (2014) Measuring spillover effects of shocks to the Alaska economy: an inter-regional social accounting matrix (IRSAM) model approach. Econ Syst Res 26(2):224-238

Sonis M, Hewings GJD (1998) Economic complexity as network complication: multiregional input-output structural path analysis. Ann Reg Sci 32:407-436

Sonis M, Hewings GJD, Sulistyowatic S (1997) Block structural path analysis: applications to structural changes in the Indonesian economy. Econ Syst Res 9(3):265-280

Stone R, Croft-Murray G (1959) Social accounting and economic models. Bowes \& Bowes Publisher, London

Takeda S, Ban K (2008) Regional disparities in the effects of trade liberalization: computable general equilibrium analysis based on an inter-regional input-output table. Research Institute of Economy, Trade and Industry (RIETI), Discussion Paper Series, 08-J-053, 1-35 (in Japanese)

\section{Submit your manuscript to a SpringerOpen ${ }^{\circ}$ journal and benefit from:}

- Convenient online submission

- Rigorous peer review

- Immediate publication on acceptance

- Open access: articles freely available online

- High visibility within the field

- Retaining the copyright to your article

Submit your next manuscript at $\boldsymbol{s p r i n g e r o p e n . c o m ~}$ 